\title{
Bazı Bitkisel Ekstraktların İki Noktalı Kırmızıörümcek, Tetranychus urticae Koch Üzerine Ovisidal ve Repellent Etkileri
}

\author{
İsmail Kasap ${ }^{1 *}$, Şahin Kök ${ }^{1}$ \\ ${ }^{1}$ Çanakkale Onsekiz Mart Üniversitesi, Ziraat Fakültesi, Bitki Koruma Bölümü, Terzioğlu Kampüsü, Çanakkale
}

15.10.2019 Geliş/Received, 11.12.2019 Kabul/Accepted

Öz

$\mathrm{Bu}$ çalışmada, tere (Lepidium sativum L.), roka (Eruca vesicaria Mill.), yarpuz (Mentha pulegium L.), fesleğen (Ocimum basilicum L.) ve biberiye (Rosmarinus officinalis L.)'den elde edilen ekstraktların iki noktalı kırmızı̈rümcek (Tetranychus urticae Koch)'nin yumurtaları ve ergin dişileri üzerine ovisidal ve repellent etkileri belirlenmiştir. Ovisidal etki testleri 5 tekerrür olacak şekilde yürütülmüş ve sayımlar uygulamadan 10 gün sonra yapılmıştır. Benzer şekilde repellent etki testleri de 5 tekerrür olarak yürütülmüş ve sayımlar ekstraktların uygulamasından 2, 6, 24, 48, 72 ve 96 saat sonra yapılmıştır. En yüksek ovisidal etki \%85.6 ile $R$. officinalis ekstraktının \%12 konsantrasyonunda elde edilirken, en yüksek repellent etki ise \%92.0 ile aynı ekstraktın aynı dozunda uygulamadan 24 saat sonra belirlenmiştir. Ayrıca genel olarak ekstraktların konsantrasyonlarının artmasıyla ovisidal ve repellent etkide de artışlar olduğu gözlenmiştir. Sonuç olarak bu çalışmada kullanılan bitkisel ekstraktların farklı konsantrasyonlarının T. urticae'nin hem yumurta hem de ergin dişileri üzerinde yüksek oranda ovisidal ve repellent etki gösterdiği belirlenmiştir.

Anahtar Kelimeler: bitkisel ekstrakt, ovisidal etki, repellent etki, Tetranychus urticae

\section{Ovicidal and Repellent Effect of Some Botanical Extracts on Two Spotted Spidermite, Tetranychus urticae Koch}

\begin{abstract}
In this study, the ovicidal and repellent effect of the extracts derived from cress (Lepidium sativum L.), garden rocket (Eruca vesicaria Mill.), pennyroyal (Mentha pulegium L.), basil (Ocimum basilicum L.) and rosemary (Rosmarinus officinalis L.) on eggs and adult females of two spotted spidermite (Tetranychus urticae Koch) were determined. The ovicidal effect tests were repeated five times and counting was performed after 10 days. Similarly, the repellent effect tests were repeated five times and counting was made after 2, 6, 24, 48, 72 and 96 hours. While the highest ovicidal effect with $85.6 \%$ was determined at $12 \%$ concentration of $R$. officinalis, the highest repellent effect with $92.0 \%$ was detected at the same concentration of the same extract after 24 hours. Also, it was generally observed that the ovicidal and repellent effect increased depending on the increases in the concentrations of extracts.
\end{abstract}

*Sorumlu Yazar (Corresponding Author): İsmail Kasap (e-posta: ikasap@comu.edu.tr)

ÇOMÜ BAP Koordinasyon Birimince desteklenmiştir. Proje numarası: FBA-2016-926 
Consequently, different concentrations of the botanical extracts using in this study showed the high ovicidal and repellent effect on both eggs and adult females of T. urticae.

Keywords: botanical extract, ovicidal effect, repellent effect, Tetranychus urticae

\section{Giriş}

Bitkilerden elde edilen uçucu yağlar, karakteristik tat ve koku özellikleri içeren, terpenoidlerin kompleks karışımları olan sekonder metabolitlerin bir grubu olarak bilinmektedirler. Bitkisel ekstraktlar böcek ve diğer arthropod zararlılara karşı insektisit, akarisit, uzaklaştırıcı, yumurtlamayı engelleyici, antifungal ve antibakteriyel olarak doğada bitkilerin korunmasında önemli rol oynamaktadır (Regnault-Roger ve ark., 2012). Bunun yanı sıra bitkilerin polen ve tohumlarının dağılmasını kolaylaştırmak ya da istenmeyenleri uzaklaştırmak için böcekleri teşvik etmesi yönünden oldukça önemli etkilere sahiptirler. Bitkisel ekstraktların pestisit olarak kullanımı göz önüne alındığında ekolojik dengeyi korumalarından dolayı sentetik pestisitlere karşı etkili bir alternatif veya tamamlayıcı oldukları ortaya çıkmaktadır (Laborda ve ark., 2013). Ayrıca bitkisel ekstraktların doğa koşullarında minimum kalıcılığı, insan ve memelilere düşük toksisitesinden dolayı birkaç istisna dışında sentetik pestisitlere göre daha güvenli olduğu bilinmektedir (Isman, 2006). Aromatik bitkilerden elde edilen bitkisel ekstraktlar sentetik pestisitlere karşı alternatif mücadele çalışmaları kapsamında yaygın bir şekilde kullanılmaktadır. Geçmişten günümüze kadar yürütülen araştırmalar yaklaşık 2000 bitkiden elde edilen ekstraktların zararlılar üzerinde insektisit etkisinin bulunduğunu göstermektedir (Koul, 2005). Genellikle tek bileşene dayalı sentetik pestisitlerin aksine bitkisel ekstraktlar birbiriyle sinerjik olarak etkileşime geçebilen ve hedef bölge direncinden kaçınmayı uygun hale getiren bileşenlerin kompleks karışımlarını içermektedir (Isman ve ark., 2011).

Tüm dünyada olduğu gibi ülkemizde de önemli zararlılardan biri olan iki noktalı kırmızı̈̈rümcek, Tetranychus urticae Koch (Acari: Tetranychidae) tarımsal ürünleri ve süs bitkilerini içeren 150 tanesi ekonomik olarak önemli 1200 den fazla konukçu bitki üzerinde zarar meydana getiren en önemli polifag türlerden biridir (Zhang, 2003). Bu türün mücadelesi çoğunlukla doğal düşmanlarını da olumsuz etkileyen sentetik pestisitlerin ya da biyolojik mücadele ajanlarının kullanılmasıyla yürütülmektedir. Ancak T. urticae'nin sentetik pestisitlere karşı kısa sürede direnç geliştirme yeteneğine sahip olması ve pestisitlerin kırmızı örümceklerin yüksek populasyonlarını baskılamada oldukça başarılı olan ve birçok pestisite karşı da hassas olan doğal düşmanlarına karşı olumsuz etkisi bir problem olarak karşımıza çıkmaktadır (Stumpf ve ark., 2001; Miresmailli ve Isman, 2006). Günümüzde T. urticae'nin dünyada 96 Türkiye'de ise 7 adet kimyasal etkili maddeye karşı direnç geliştirdiği belirlenmiştir (DARP, 2012). Bu sebeplerden dolayı seçici, biyolojik olarak doğada parçalanabilen ve hedef olmayan organizmalara karşı daha az olumsuz etkisi bulunan bitkisel ekstraktlar kırmızı örümceklerin mücadelesi için iyi bir alternatif haline gelmektedir (Isman, 2000).

Bitkilerden elde edilen ve zararlı türlere karşı kullanılma potansiyeli olduğu belirlenen farklı ekstraktların T. urticae üzerine toksik etkilerinin yanı sıra repellent ve ovisidal etkilerinin de incelendiği çalışmalar gerçekleştirilmiştir (Wang ve ark., 2007; Erdoğan ve ark., 2010; Kumral ve ark., 2010; Yanar ve ark., 2011; Erdoğan ve ark., 2012; Motazedian ve ark., 2012; Derbalah ve ark., 2013; Ghaderi ve ark., 2013; Yorulmaz Salman ve ark., 2014; 2015; Akyaz1 ve ark., 2015; Vicentini ve ark., 2015; Kasap ve ark., 2016; Kök ve ark., 2016; Pavela, 2016; Kasap ve Kök, 2019). Dünyada ve ülkemizde yapılan çalışmalar göz önüne alındığında pestisitlerin hem insan sağlığı hem de çevre üzerindeki gittikçe artan ciddi zararlı etkilerinden dolayı alternatif mücadele yöntemlerinin başında gelen bitkilerden elde edilen ekstraktlar olduk- 
ça umut vaat edici sonuçlar ortaya çıkarmaktadır. Bu bağlamda bitkilerden elde edilen ekstraktların insektisit özelliklerinin yanı sıra diğer etkilerini de ortaya çıkarabilmek için bu çalişmada tere (Lepidium sativum L.), roka (Eruca vesicaria Mill.), yarpuz (Mentha pulegium L.), fesleğen (Ocimum basilicum L.) ve biberiye (Rosmarinus officinalis L.) ekstraktlarının $T$. urticae'nin yumurtaları ve ergin dişileri üzerine ovisidal ve repellent etkileri belirlenmiştir.

\section{Materyal ve Yöntem}

\subsection{Denemelerde Kullanılan T. urticae Bireylerinin Yetiștirilmesi}

Ovisidal ve repellent etki denemelerinde kullanılan $T$. urticae stok kültürünün elde edilmesi amacıyla bireyler Çanakkale ilindeki tarım alanlarından toplandıktan sonra $25 \pm 2{ }^{\circ} \mathrm{C}, \% 70 \pm 10$ orantılı nem ve 16:8 1şıklandırma süresine ayarlı iklimlendirme odasında fasulye (Phaseolus vulgaris L.) bitkisi üzerinde yetiştirilmiştir. Denemelerde kullanılabilmesi amacıyla T. urticae populasyonunun en az iki nesil boyunca belirtilen şartlarda çoğalması sağlanmıştır. Daha sonra elde edilen stok kültür üzerinden denemelerde kullanılan T. urticae'ye ait ergin dişi bireyler ve yumurtalar elde edilmiştir.

\subsection{Bitkisel Ekstraktlarının Hazırlanması}

Bu çalışmada kullanılan biberiye (R. officinalis), fesleğen (O. basilicum) ve yarpuz (M. pulegium) ekstraktları Telci ve ark. (2010)'un uyguladığı yöntem modifiye edilerek elde edilmiştir. Bu yönteme göre bitkiler serin ve gölge alanlarda sabit ağırlığa gelinceye kadar kurutulduktan sonra ögütülerek toz haline getirilmiştir. Daha sonra 50'şer gr kuru örnek üzerine 500 $\mathrm{ml}$ saf su eklenerek Neo-Clevenger cihazına alınmış ve 2-6 saat süreyle distilasyon işlemi gerçekleştirilmiştir. Bu işlem sonunda elde edilen ekstraktlar cam şişeler içerisinde $+4{ }^{\circ} \mathrm{C}$ 'de muhafaza edilmiştir. Roka (E. vesicaria) ve tere (L. sativum) ekstraktlarının elde edilmesinde Gökçe ve ark. (2007)'nın yöntemi değiştirilerek uygulanmıştır. Bu amaç doğrultusunda kurutulduktan sonra toz haline getirilen bitkilerden 100 'er gr kuru örnek erlenmayer içerisinde çözücü kullanılarak 48 saat süre ile çalkalayıcıda bekletildikten sonra önce ince bir tül daha sonra filtre (Whatman No 1) kağıdından süzülerek posasının uzaklaştırılması sağlanmıştır. Elde edilen karışımdaki çözücü yatık tip rotary evaporatör ile uzaklaştırıldıktan sonra elde edilen ekstraktlar cam şişeler içerisinde $+4{ }^{\circ} \mathrm{C}$ 'de muhafaza edilmiştir. Elde edilen bitkisel ekstraktlar \%0.3 Tween 20 içeren saf su içerisinde seyreltilerek manyetik karıştırıcıda \%1, \%6 ve $\% 12$ konsantrasyonları hazırlanmıştır. Kontrol gruplarında da \%0.3 Tween 20 içeren saf su kullanılmıştır.

\subsection{Bitkisel Ekstraktların T. urticae Yumurtaları Üzerine Ovisidal Etkisi}

Bitkisel ekstraktların ovisidal etkisini belirlemek amacıyla Akyazı ve ark. (2015)'nın uyguladığ 1 yöntem temel alınarak ekstraktların \%1, \%6 ve \%12'lik konsantrasyonları kullanılmıştır. $\mathrm{Bu}$ amaç doğrultusunda $3 \mathrm{~cm}$ çapındaki fasulye yaprak diskleri üzerinde 10 adet ergin dişi $T$. urticae bırakılmış ve yumurta bırakmaları için 24 saat süre ile beklenmiştir. Bu süre sonunda ergin bireyler ve fazla olan yumurtalar yaprak diskleri üzerinden uzaklaştırılmış ve son olarak 25 adet yumurta kalması sağlanmıştır. T. urticae yumurtası bulunan yaprak diskleri ekstraktların faklı konsantrasyonlarına 5 sn süre ile daldırılmış ve daha sonra oda sıcaklığında kuruması için beklenmiştir. Daha sonra diskler tabanında nemlendirilmiş pamuk bulunan plastik petrilere alınarak denemeler başlatılmıştır. Denemeler 5 tekerrür olarak yürütülmüş olup kontrol gruplarında \%0.3 Tween 20 içeren saf su kullanılmıştır. Sayımlar 10 gün sonunda yapılarak açılmayan yumurtalar ölü olarak değerlendirilmiştir. 


\subsection{Bitkisel Ekstraktların T. urticae Ergin Dişi Bireyleri Üzerine Repellent Etkisi}

Bitkisel ekstraktların T. urticae ergin dişi bireyleri üzerindeki repellent etkisi Akyazı ve ark. (2015)'nın uyguladığı yöntem esas alınarak belirlenmiştir. Ekstraktların T. urticae ergin dişileri üzerindeki repellent etkisini belirlemek amaciyla ekstraktların \%1, \%6, \%12 konsantrasyonları Akyazı ve ark. (2015)'nın kullandığı yönteme göre uygulanmıştır. Bu doğrultuda $3 \mathrm{~cm}$ çapındaki fasulye yaprak disklerinin yarısı ekstraktların farklı konsantrasyonlarına 5 sn süre ile daldırıldıktan oda sıcaklığında kurumaya bırakılmıştır. Kuruyan yaprak disklerinin diğer yarısı da \%0.3 Tween 20 içeren saf suya aynı yöntemle daldırıldıktan sonra kuruması beklenmiştir. Kuruyan yaprak diskleri taban kısmında nemlendirilmiş pamuk bulunan plastik petriler içerisinde yaprağın alt yüzeyi üste gelecek şekilde yerleştirilmiştir. Daha sonra 10 adet ergin dişi T. urticae bireyleri yaprağın ekstraktlar ve saf suyun uygulandığ 1 orta sınır noktasına bırakılmış ve 2, 6, 24, 48, 72, 96 saat sonra kontrol edilerek yaprak diskinin hangi tarafında bulunduğu kaydedilmiştir. Repellent etki denemeleri 5 tekerrür olacak şekilde yürütülmüştür.

\subsection{Verilerin Değerlendirilmesi}

$\mathrm{Bu}$ çalışmanın sonucunda elde edilen verilerle MiniTab 17 programında istatistik olarak değerlendirilmiştir. Repellent etki denemelerinden elde edilen sonuçlar Obeng-Ofori ve ark. (1997) tarafından geliştirilen \% repellent etki indeksine [Repellent etki $(\%)=[(\mathrm{Nc}-\mathrm{Nt}) /$ $(\mathrm{Nc}+\mathrm{Nt})] \times 100(\mathrm{Nc}$ : kontrol yönüne giden birey sayıs1; $\mathrm{Nt}$ : uçucu yağ veya bileşen yönüne giden birey sayıs1)] göre hesaplanmıştır. Elde edilen ham veriler varyans analizine tabi tutulmuş (One-Way ANOVA) ve her ekstrakt için uygulanan konsantrasyonlar kendi aralarında karşılaştırılarak değerlendirilmiştir. Farklı bulunan değerlere Tukey Testi uygulanmıştır.

\section{Bulgular ve Tartışma}

Tere (L. sativum), roka (E. vesicaria), yarpuz (M. pulegium), fesleğen (O. basilicum) ve biberiye ( $R$. officinalis) bitkilerinden elde edilen ve farklı konsantrasyonları kullanılan ekstraktların T. urticae'nin ergin dişi bireylerinin bıraktığı yumurtalar üzerindeki ovisidal etkilerinin farklı oranlarda olduğu tespit edilmiştir. En düşük ovisidal etki genellikle ekstraktların en düşük konsantrasyonlarında elde edilirken en yüksek ovisidal etki ise ekstraktların en yüksek (\%12) konsantrasyonlarında tespit edilmiştir. E. vesicaria'nın \%1 konsantrasyonunda ovisidal etki \%11.2 olarak belirlenmiş ve $R$. officinalis'in \%12 konsantrasyonunda ise \%85.6 olarak tespit edilmiştir $(\mathrm{P}<0,05)$. Test edilen tüm eksraktların her birinin kendi içerisinde farklı konsantrasyonları arasında istatistik olarak fark olduğu belirlenmiştir $(\mathrm{P}<0,05)$. Bütün ekstraktlarda konsantrasyonların artışıyla birlikte ovisidal etkide de artış olduğu tespit edilmiştir. Sonuç olarak bu çalışmada test edilen bütün ekstraktların $T$. urticae'nin yumurtaları üzerinde önemli oranda ovisidal etkiye sahip olduğu belirlenmiştir. Ekstraktların farklı konsantrasyonlarının göstermiş olduğu ovisidal etkiler Çizelge 3.1'de verilmiştir. 
Çizelge 3.1. Bitki ekstraklarının T. urticae yumurtaları üzerine ovisidal etkisi (ort. \pm s.h.)

\begin{tabular}{|c|c|c|c|c|c|}
\hline \multirow{2}{*}{$\begin{array}{c}\text { Konsantrasyon } \\
(\%)\end{array}$} & $\begin{array}{l}\text { Lepidium } \\
\text { sativum }\end{array}$ & $\begin{array}{c}\text { Eruca } \\
\text { vesicaria }\end{array}$ & $\begin{array}{l}\text { Ocimum } \\
\text { basilicum }\end{array}$ & $\begin{array}{l}\text { Mentha } \\
\text { pulegium }\end{array}$ & $\begin{array}{c}\text { Rosmarinus } \\
\text { officinalis }\end{array}$ \\
\hline & $\begin{array}{c}\text { Ovisidal Etki } \\
(\%)\end{array}$ & $\begin{array}{c}\text { Ovisidal Etki } \\
(\%)\end{array}$ & $\begin{array}{c}\text { Ovisidal Etki } \\
(\%)\end{array}$ & $\begin{array}{c}\text { Ovisidal Etki } \\
(\%)\end{array}$ & $\begin{array}{c}\text { Ovisidal Etki } \\
(\%)\end{array}$ \\
\hline 1 & $20.0 \pm 2.83 \mathrm{c}$ & $11.2 \pm 1.79 \quad \mathrm{c}$ & $32.0 \pm 4.00 \quad b$ & $32.0 \pm 2.83 \mathrm{c}$ & $52.8 \pm 5.22$ \\
\hline 6 & $34.4 \pm 2.19$ & $21.6 \pm 2.19$ & $62.4 \pm 2.19$ & $44.8 \pm 3.35$ & $65.6 \pm 6.07$ \\
\hline 12 & $56.8 \pm 3.35$ & $37.6 \pm 2.19$ & $68.0 \pm 4.00$ & $65.6 \pm 3.58$ & $85.6 \pm 8.29$ \\
\hline
\end{tabular}

*Aynı sütunda ayrı harflerle gösterilen ortalamalar arasındaki fark istatistik olarak önemli bulunmuştur $(\mathrm{P}<0,05)$.

Farklı bitkilerden elde edilen ekstraktların $T$. urticae yumurtaları üzerindeki ovisidal etkilerini inceleyen önceki çalışmalarda önemli sonuçlar elde edilmiştir. Akyazı ve ark. (2015) Prunus laurocerasus L. (Rosaceae) bitkisinden elde edilen yaprak, çiçek ve tohum ekstraklarının $T$. urticae'nin yumurtaları üzerindeki ovisidal etkilerini araştırmışlardır. Çalışmada en düşük ovisidal etki çiçek ekstraktının \%1 konsantrasyonunda elde edilirken, en yüksek ovisidal etki ise tohum ekstraktının \%10 kosantrasyonunda elde edilmiştir. Çalışmada test edilen bitkinin farklı kısımlarından elde edilen ekstraklarda doz arttıkça etki oranında da artışlar olduğu bildirilmiştir. Yorulmaz Salman ve ark. (2014) Salvia officinalis L. ve bu çalışmada da kullanılan $R$. officinalis bitkilerinden elde edilen ekstraktların T. urticae yumurtaları üzerindeki ovisidal etkilerini araştırdıkları çalışmalarında ekstraktların $\% 1, \% 3, \% 6$ ve $\% 12$ konsantrasyonlarını test etmişlerdir. Çalışma sonucunda \%12 konsantrasyonda $S$. officinalis ekstraktının $\% 30.2, R$. officinalis ekstraktının ise \%82.2 ovisidal etki gösterdiğini bildirmişlerdir. Benzer sonuçlar $R$. officinalis için bu çalışmada da elde edilmiştir. Bu çalışmada $R$. officinalis ekstraktının uygulandığı testlerde 10 gün sonra yapılan sayımlarda aynı konsantrasyonda \%85.6 oranında ovisidal etki tespit edilmiştir. Ghaderi ve ark. (2013) tarafından yürütülen diğer çalışmada Anisosciadium orientale DC., Ptelea viscosa L., Scaligeria meifolia Boiss. ve Trigonella elliptica Boiss. bitkilerinden elde edilen ekstraktların $T$. urticae yumurtaları üzerindeki ovisidal etkisi incelenmiştir. Çalışmada en yüksek ovisidal etkinin S. meifolia testlerinde belirlendiği ve bunu diğer ekstraktların izlediği bildirilmiştir. Sonuç olarak test edilen bütün ekstraktların yüksek ovisidal etkilerinin olduğu rapor edilmiştir.

Diğer taraftan bu çalışmada, farklı bitkilerden elde edilen ekstraktların \%1, \%6 ve \%12 konsantrasyonlarının 2, 6, 24, 48 ve 72. saatlerde iki noktalı kırmızıörümcek, T. urticae'nin ergin dişi bireyleri üzerindeki repellent etkisi belirlenmiştir. Repellent etki testleri sonucunda farklı dozlarda ve farklı sürelerde uygulanan ekstraktların farklı oranlarda etki gösterdiği tespit edilmiştir. Tere (L. sativum) bitkisinden elde edilen ekstraktın uygulanan konsantrasyonlarda farklı oranlarda etki gösterdiği ancak konsantrasyonlar arasında istatistik olarak herhangi bir fark olmadığ 1 belirlenmiştir $(\mathrm{P}<0,05)$. Ekstraktın gösterdiği repellent etkinin süre ile birlikte artış gösterdiği en yüksek etkiyi ise 24 . saat sonunda gösterdikten sonra sürenin ilerlemesiyle birlikte etkinin de azalma eğiliminde olduğu belirlenmiştir. Roka (E. vesicaria)'dan elde edilen ekstraktın farklı saatlerde yapılan sayımlarında farklı dozları arasında genellikle istatistik olarak herhangi bir fark gözlenmezken 24. saat sonunda yapılan sayımlarda en yüksek repellent etkinin ekstraktın \%12 konsantrasyonunda belirlendiği ve dozlar arasında istatistik olarak fark olduğu tespit edilmiştir $(\mathrm{P}<0,05)$. Ekstraktın repellent etkisinin $L$. sativum'da olduğu gibi 24. saate kadar süre artışıyla birlikte arttı̆̆ 1 ve bu süreden sonra ise azalma gösterdiği gözlenmiştir. O. basilicum'dan elde edilen farklı zamanlarda farklı konsantrasyonlarında yapılan sayımlarda dozlar arasında genellikle istatistik olarak farklar olduğu belirlenmiştir. En yüksek repellent etki 24 . saat sonunda yapılan sayımda ekstraktın $\% 12$ konsantrasyonunda elde edilmiş ve uygulama dozların istatistik olarak farklı gruplarda yer aldığı gözlenmiştir $(\mathrm{P}<0,05)$. 
Benzer sonuçlar M. pulegium'dan elde edilen ekstraktın testlerinde de elde edilmiştir. Bu testlerde genellikle uygulama dozlarının artmasıyla birlikte repellent etkide de artışlar olduğu tespit edilmiştir. En yüksek repellent etki 24 . saat sonunda yapılan sayımlarda \%12 konsantrasyonunda elde edilirken bu saatte yapılan sayımlarda uygulama dozlarının istatistik olarak farklı gruplarda yer aldığ 1 belirlenmiştir $(\mathrm{P}<0,05)$. Bu süreden sonra yapılan sayımlarda repellent etkinin zaman ilerledikçe azalma gösterdiği tespit edilmiştir. $R$. officinalis'den elde edilen ekstraktın farklı zamanlarda farklı konsantrasyonlarının değerlendirildiği testlerde genellikle konsantrasyonların istatistik olarak farklı gruplarda yer aldığı belirlenmiştir $(\mathrm{P}<0,05)$. Repellent etki testlerinde 24. saat sonunda yapılan sayımlarda en yüksek etki ekstraktın \%12 konsantrasyonunda elde edilmiş ve bu sürede konsantrasyonların istatistik olarak farklı gruplarda yer aldığ gözlenmiştir $(\mathrm{P}<0,05)$. Diğer ekstraktlarda olduğu belirli bir süreden sonra repellent etkide azalma olduğu belirlenmiştir. Ekstraktların farklı konsantrasyonlarının göstermiş olduğu repellent etkiler Çizelge 3.2'de verilmiştir.

Çizelge 3.2. Bitki ekstraklarının T. urticae ergin dişileri üzerine repellent etkisi (ort..s.h.)

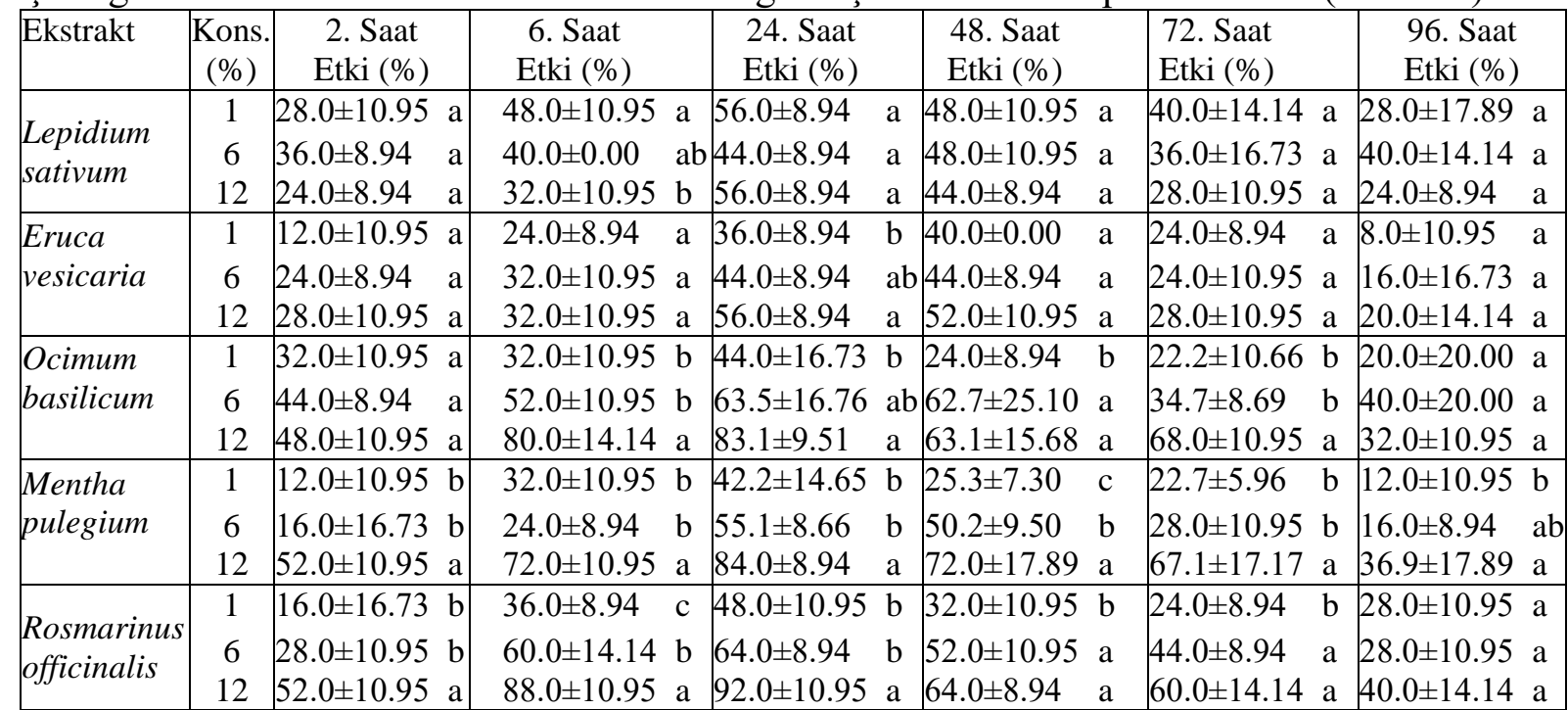

*Aynı sütunda ayrı harflerle gösterilen ortalamalar arasındaki fark istatistik olarak önemli bulunmuştur $(\mathrm{P}<0,05)$.

Genel olarak bu çalışmada farklı sürelerdeki repellent etkisi incelenen ekstraktların farklı dozlarının uygulandığ 1 testlerde, en yüksek repellent etkinin ekstraktların \%12 konsantrasyonlarında elde edildiği belirlenmiştir. Uygulamalardan sonra farklı sürelerde yapılan sayımlarda repellent etkinin genellikle 24. saate kadar önemli oranda artış gösterdiği ve bu süreden sonra azalma eğiliminde olduğu tespit edilmiştir. Bitkilerden elde edilen ekstrakların tarımsal zararlılar üzerindeki insektisit etkisini inceleyen çalışmaların yanı sıra son yıllarda repellent etkileri üzerine de çalışmalar yürütülmektedir. Kheradmand ve ark. (2015) çalışmalarında karanfil (Syzygium aromaticum Thun. var. Nelson) (Myrtaceae), kimyon (Cuminum cyminum L. var. Kerman) (Apiaceae) ve nane ( Mentha spicata L. var. Crispa) (Lamiaceae)'den elde edilen ekstraktların T. urticae üzerine etkilerini incelemiş̧lerdir. Test sonuçlarına göre en yüksek repellent etki sırasıyla karanfil, nane ve kimyon ekstraktlarından elde edilmiş ve konsantrasyon arttıkça repellent etkinin artış gösterdiği vurgulanmıştır. Benzer sonuç bu çalışmada da ortaya çıkmış ve genellikle konsantrasyon artışı ile birlikte repellent etkide de artış gözlenmiştir. Yeşilayer ve Aslan (2018) Labiatae (Lamiaceae) cinsine bağlı Origanum onites L., O. vulgare L., O. majorana L., Thymbra spicata ve Thymus vulgaris L., kekik türlerinin ekstraktlarının T. urticae'ye karşı repellent etkilerini incelemişlerdir. Repellent etki testleri sonucunda 24 saat sonra yapılan sayımlarda ekstraktların \%71.5 ile \%98.4 arasında değişen oranlarda etki gösterdiği tespit edilmiştir. Çalışmada ayrıca T. urticae üzerindeki en yüksek repellent 
etkiyi $O$. onites ekstraktının gösterdiği bildirilmiştir. Yorulmaz Salman ve ark. (2015) T. urticae'nin nimf ve ergin bireyleri üzerine Hyssopus officinalis L., Lavandula $x$ intermedia Emeric ex Loisel., Rosmarinus officinalis L. ve Salvia officinalis L. ekstratlarının repellent etkisini incelemişlerdir. Repellent etki testlerinin sonucunda ekstraktların nimflere karşı erginlere göre daha yüksek etki gösterdiği bildirilmiştir. Nimflerde yapılan sayımlarda en yüksek etki genellikle bütün ekstraktlar için en yüksek doz olan $10 \mathrm{ml} / \mathrm{l}$ 'de elde edilirken erginlerde ise en yüksek repellent etki $H$. officinalis ve L. intermedia ekstraktının aynı dozunda belirlenmiştir. Sonuç olarak çalışmada kullanılan bitkilerden elde edilen ekstraktların T. urticae'nin hem nimf hem de ergin dönemleri üzerine önemli oranda repellent etki gösterdiği bildirilmiştir. Yürütülen mevcut çalışmamızda bu çalışmadan farklı olarak $R$. officinalis ekstraktının \%12 konsantrasyonunun ergin $T$. urticae'lere karşı önemli oranda repellent etki gösterdiği tespit edilmiştir. Mozaffari ve ark. (2013) bu çalışmada da kullanılan M. pulegium ekstraktının T. urticae üzerine farklı etkilerini incelemişlerdir. Çalışmada ekstraktın farklı konsantrasyonları test edilmiş olmasına rağmen konsantrasyonlar arasında istatistiksel olarak bir fark bulunmadığı bildirilmiştir. Yürüttüğümüz mevcut çalışmada ise 24 saat sonra yapılan sayımlarda $M$. pulegium ekstraktının en yüksek repellent etkisi \%12 konsantrasyonunda elde edilirken dozlar arasındaki fark istatistiksel olarak önemli bulunmuştur. Bunun durumun ise çalışmalarda test edilen dozların birbirinden önemli oranda farklı olmasından kaynaklandığı düşünülmektedir. Kök ve ark. (2016) tarafından yürütülen diğer çalışmada ise ülkemizde çay ağacı olarak da bilinen Melaleuca alternifolia (Myrtaceae)'dan elde edilen Fungatol ve Gamma-T-ol ekstraktlarının farklı konsantrasyonlarının T. urticae üzerindeki repellent etkisi belirlenmiştir. Çalışma sonucunda her iki ekstraktın da 2 ve 24 saat sonra yapılan sayımlarda önemli oranlarda repellent etki gösterdiği ve sürenin ilerlemesiyle de etkinin azaldığı bildirilmiştir. Mevcut çalışmamızda da benzer sonuçlar gözlenmiş olup testlerde kullandığımız eksraktların repellent etkilerinin 24. saate kadar artış gösterdikten sonra sürenin ilerlemesiyle azalma eğiliminde olduğu tespit edilmiştir.

\section{Sonuç}

Sonuç olarak bu çalışmada test edilen tere (L. sativum), roka (E. vesicaria), yarpuz (M. pulegium), fesleğen ( $O$. basilicum) ve biberiye ( $R$. officinalis) bitkilerinden elde edilen farkl konsantrasyonlardaki bitkisel ekstraktların hem dünya hem de ülkemizde önemli tarımsal zararlılardan biri olan $T$. urticae üzerine yüksek oranda repellent ve ovisidal etkilerinin olduğu belirlenmiştir. Tarımsal üretimde zararlılar ile mücadele amacıyla yoğun olarak kullanılan pestisitlerin insan sağlığı ve çevre üzerine artan ve geri dönülemez seviyelere ulaşan olumsuz etkileri göz önüne alındığında, bu kimyasallara karşı alternatif bir yöntem olarak karşımıza çıkan bitkisel ekstraktların önemi gün geçtikçe artmaktadır. Bu çalışmada elde edilen sonuçların T. urticae üzerine önemli etkileri olduğu tespit edilen bitkisel ekstraktların geliştirilerek tarımsal üretimde daha yaygın kullanılmasına, insan ve çevre sağlığına duyarlı mücadele yöntemlerinin kazanılmasına katkı sağlayabileceği düşünülmektedir.

\section{Teșekkür}

Bu çalışma Çanakkale Onsekiz Mart Üniversitesi Bilimsel Araştırma Projeleri Koordinasyon Birimince desteklenmiştir. Proje Numarası: FBA-2016-926. Desteklerinden dolayı Çanakkale Onsekiz Mart Üniversitesi Bilimsel Araştırma Projeleri Komisyonu'na teşekkür ederiz. 


\section{Kaynakça}

Akyazı R., Soysal M., Hassan E., 2015. Toxic and Repellent Effects of Prunus laurocerasus L. (Rosaceae) Extracts against Tetranychus urticae Koch (Acari: Tetranychidae).Turkish Journal of Entomology, 39(4): 367-380.

DARP 2012. 10 October 2019. Database of Arthropods Resistance to Pesticides. http://www.pesticideresistance.org/DB/index.html

Derbalah A.S., Keratrum A.Y., El-Dewy M.E., El-Shamy E.H., 2013. Efficacy of Some Insecticides and Plant Extracts against Tetranychus urticae under Laboratory Conditions. Egyptian Journal of Plant Protection Research, 1(3): 47-69.

Erdoğan E., Saltan G., Sever B., 2010. Acı Biber (Capsicum annum L.) Ekstraktının İki Noktalı Kırmızıörümcek, Tetranychus urticae Koch (Arachnida: Tetranychidae)'ye Akarisit Etkisi. Bitki Koruma Bülteni, 50: 35-43.

Erdoğan P., Yıldırım A., Sever B., 2012. Investigations on the Effects of Five Different Plant Extracts on the Two- Spotted Mite, Tetranychus urticae Koch. (Arachnida: Tetranychidae). Psyche, 2012: 1-5.

Ghaderi S., Minaei K., Rowshan V., Mohammad G., 2013. Toxicity and Ovicidal Activity of Different Plant Extracts on Two-Spotted Spider Mite, Tetranychus urticae Koch (Acari: Tetranychidae). Archiv für Phytopathologie und Pflanzenschutz, 46(1): 120-126.

Gökçe A., Whalon M.E., Çam H., Yanar Y., Demirtaş İ., Gören N., 2007. Contact and Residual Toxicities of 30 Plant Extracts to Colorado Potato Beetle Larvae. Archives of Phytopathology and Plant Protection, 40(6): 441-450.

Isman M.B., 2000. Plant Essential Oils for Pest and Disease Management. Crop Protection, 19: 603-608.

Isman M.B., 2006. Botanical Insecticides, Deterrents, and Repellents in Modern Agriculture and an Increasingly Regulated World. Annual Review of Entomology, 51: 45-66.

Isman M.B., Miresmailli S., Machial C., 2011. Commercial Opportunities for Pesticides based on Plant Essentials Oils in Agriculture, Industry and Consumer Products. Phytochemistry Reviews, 10: 197-204. 
Kasap İ., Kök Ş., 2019. Bazı Bitki Ekstraktlarının İki Noktalı Kırmızıörümcek, Tetranychus urticae Koch Üzerine İnsektisit Etkisinin Belirlenmesi. ÇOMÜ Ziraat Fakültesi Dergisi, 7(1): 137-144.

Kasap İ., Kök Ş., Hassan E., 2016. Effect of Fungatol and Gamma-T-ol from Melaleuca alternifolia (Maiden \& Betche) Cheel on Aphis gossypii Glover (Hemiptera: Aphididae) and Tetranychus urticae Koch (Acari: Tetranychidae). Turkish Journal of Entomology, 40(2): 117-123.

Kheradmand K., Beynaghi S., Asgari S., Sheykhi Garjan A., 2015. Toxicity and Repellency Effects of Three Plant Essential Oils Against Two-spotted Spider Mite, Tetranychus urticae (Acari: Tetranychidae). Journal of Agricultural Science and Technology, 17: 12231232.

Koul O., 2005. Insect Antifeedants. CRC Press, 1005 pp. Florida.

Kök Ş., Erdoğmuş A. , Koyun A., Kasap İ., 2016. Melaleuca alternifolia (Myrtaceae)'dan Elde Edilen Fungatol ve Gamma-T-ol Ekstraktlarının Laboratuar Koşullarında Tetranychus urticae Koch (Acari: Tetranychidae)'ye Karşı Repellent Etkisi. ÇOMÜ Ziraat Fakültesi Dergisi, 4(1): 93-98.

Kumral N.A., Çobanoğlu S., Yalçın C., 2010. Acaricidal, Repellent and Oviposition Deterrent Activities of Datura stramonium L, against Adult Tetranychus urticae (Koch). Journal of Pest Science, 83: 173-180.

Laborda R., Manzanoa I., Gamónb M.,, Gavidiac I., Pérez-Bermúdezc P., Boluda R., 2013. Effects of Rosmarinus officinalis and Salvia officinalis Essential Oils on Tetranychus urticae Koch (Acari: Tetranychidae). Industrial Crops and Products. 48: 106-110.

Miresmailli S., Isman M.B., 2006. Efficacy and Persistence of Rosemary Oil as an Acaricide against Twospotted Spider Mite (Acari: Tetranychidae) on Greenhouse Tomato. Journal of Economic Entomology, 99: 2015-2023.

Motazedian N., Ravan S., Bandani A.R., 2012. Toxicity and Repellency Effects of Three Essential Oils against Tetranychus urticae Koch (Acari: Tetranychidae). Journal of Agricultural Science and Technology, 14: 275-284. 
Mozaffari F., Abbasipour H., Sheikhi Garjan A., Saboori A., Mahmoudvand M., 2013.

Toxicity and Oviposition Deterrence and Repellency of Mentha pulegium (Lamiacaeae) Essential Oils against Tetranychus urticae Koch (Teteranychidae). TEOP, 16(5): 575581.

Obeng-Ofori D., Adler C., Reichmuth C., 1997. Toxicity and Repellency of 1,8-cineole, Eugenol and Camphor against Stored Product İnsects. Mitteilungen Der DGaaE, 11(1-6): 259-264.

Pavela R., 2016. Acaricidal Properties of Extracts of Some Medicinal ond Culinary Plants against Tetranychus urticae Koch. Plant Protection Sciemce, 52(1): 54-63.

Regnault-Roger C., Vincent C., Arnason J.T., 2012. Essential Oils in Insect Control: Lowrisk Products in A High-Stakes World. Annual Review of Entomology, 57: 405-424.

Stumpf N., Zebitz C.P.W., Kraus W., Moores G.D., Nauen R., 2001. Resistance to Organophosphates and Biochemical Genotyping of Acetylcholinesterases in Tetranychus urticae (Acari: Tetranychidae). Pest Biochemistry and Physiology, 69: 131-142.

Telci I., Demirtas I., Bayram E., Arabacı O., Kaçar O., 2010. Environmental Variation on Aroma Components of Pulegone/Piperitone Rich Spearmint (Mentha spicata L.). Industrial Crops and Products, 32: 588-592.

Vicentini V.B., Pratissoli D., de Queiroz V.T., Costa A.V., Pinheiro P.F., Zinger F.D., Rondelli V.M., 2015. Ethanol Extract of Cymbopogon winterianus on Mortality and Number of Eggs of Tetranychus urticae. Ciência Rural, Santa Maria, 45(7): 1154-1159.

Wang Y.N., Shi G.L., Zhao L.L., Liu S.Q., Yu T.Q., Clarke S.R., Sun J.H., 2007. Acaricidal Activity of Juglans regia Leaf Extracts on Tetranychus viennensis and Tetranychus cinnabarinus (Acari: Tetranychidae). Journal of Economic Entomology, 100(4): 12981303.

Yanar D., Kadioglu I., Gokce A., 2011. Acaricidal Effects of Different Plant Parts Extracts on Two-Spotted Spider Mite (Tetranychus urticae Koch). African Journal of Biotechnology, 10(55): 11745-11750.

Yeşilayer A., Aslan H.N., 2018. Bazı Kekik Türlerinden Elde Edilen Uçucu Yağların İki Noktalı Kırmızı Örümcek (Tetranychus urticae Koch, Acari: Tetranychidae) Üzerine Repellant Etkisi. ÇOMÜ Ziraat Fakültesi Dergisi, 6(2): 13-20. 
Yorulmaz Salman S., Saritas S., Kara N., Ay R., 2014. Acaricidal and Ovicidal Effects of Sage (Salvia officinalis L.) and Rosemary (Rosmarinus officinalis L.) (Lamiaceae) Extracts on Tetranychus urticae Koch (Acari: Tetranychidae). Journal of Agricultural Science, 20: 358-367.

Yorulmaz Salman S., Saritas S., Kara N., Aydinli F., Ay R., 2015. Contact, Repellency and Ovicidal Effects of Four Lamiaceae Plant Essential Oils against Tetranychus urticae Koch (Acari: Tetranychidae). TEOP, 18(4): 857-872.

Zhang Z., 2003. Mites of Greenhouses: Identification, Biology and Control. CABI Publishing, Cambridge, PP. 54-61. 